\title{
Survey on Attitude Towards Pervasive Games
}

\author{
Alf Inge Wang ${ }^{1}$, Hong Guo ${ }^{2}$, Meng Zhu ${ }^{3}$, Are Sæterbø Akselsen ${ }^{4}$, and Kenneth Kristiansen ${ }^{5}$ \\ Dept. of Computer and Information Science, \\ Norwegian University of Science and Technology \\ Trondheim, Norway \\ ${ }^{1}$ alfw $/{ }^{2}$ guohong $/{ }^{3}$ zhumeng ${ }^{4}$ aresater $/{ }^{5}$ kennetkr @idi.ntnu.no
}

\begin{abstract}
Pervasive gaming as a research field has been attracting more and more attentions from researchers and practitioners. However, there is no much work on player's general attitude to pervasive games even this is an important aspect of understanding player enjoyment of pervasive games. We created a survey where we wanted to investigate people's attitude towards pervasive games. The survey included questions on people's general attitude towards pervasive games, their attitude towards some particular game concepts and game modes, and their attitude towards some specified pervasive elements in games. The result from this survey is presented in this paper, along with discussions about the results.
\end{abstract}

Keywords-component; Pervasive games, Mobile games, Location-awareness, Survey.

\section{INTRODUCTION}

The goal of pervasive games is to bring computer entertainment back to the real world [1]. Pervasive games employ pervasive technology like location positioning and utilizing player context in real world, and thus produce high immersion. Pervasive gaming as a research field has been attracting more and more attention from researchers and practitioners. Many prototypes have been developed e.g. [2, 3] to validate pervasive techniques and concept, and a few pervasive games like BotFighter [4] have been a commercial success. Still, researchers are looking for how to design pervasive games that are fun and engaging for the user [5] to make pervasive games mainstream. Our approach to this problem is to ask the potential users about what they would like to see in a pervasive game and determine the pervasive components in a game that are perceived as positive and what components are perceived as negative.

What the term Pervasive means is still a question. The term Pervasive Game has been defined differently in literature. In [6], Nieuwdorp tried to summarize different definitions of the term and ended up with a conclusion that "we need to let go of the notion of coining the ultimate definition of pervasive games, and instead ask ourselves what makes a game pervasive." His argument brings a research question to the field that what the essential characteristics of pervasive games are. Guo et al. tried to give an answer to this question by proposing TeMPS [7]. TeMPS is a conceptual framework to characterize pervasive games through the four dimensions: Temporality, Mobility, Perceptibility, and Sociality. Jegers explored pervasiveness from player experience perspective [8] and adapted the GameFlow model [9] to pervasive gaming, and updated criteria of elements in general GameFlow Model according to attributes of pervasive gaming. This kind of work in literature does help improve understanding pervasiveness. However all of them are more based on theoretical analysis, while usercentered work from player attitude perspective is neglected. An interesting question from this perspective is "Is pervasive gaming attractive to players of games and people in general?" Prototypes like $[2,3]$ were just evaluated by a small group of players (normally the participants of field test). Further, the commercial success of games like BotFighter [4] validated the expected player interests to pervasive gaming. Still we lack surveys targeting general population that find answers to the following research questions:

- RQ1: Is pervasive gaming an attractive concept to gamers and people in general?

- $\quad$ RQ2: Which type of games and game modes are most interesting for the public?

- RQ2: Which characteristics of pervasive games do players desire?

We believe answer to these questions could further improve our understanding of pervasive gaming by taking gamers' attitude to this concept into account, which could also provide support for creating conceptual frameworks. A survey targeting general population in Norway was done by us for this purpose. We created a questionnaire about pervasive games that was distributed to 655 persons all over Norway, where we received 168 complete responses. The survey was first tried out on 25 persons to test the quality of the questions, and then after some improvements on 10 other persons. After a final revision, the final questionnaire was distributed. This paper presents the results from this survey along with a discussion on aspects regarding pervasive gaming.

The paper is organized as follows. Section II presents the related work, Section III the survey including the demographics, Section IV the results of the survey, Section V discusses the results, and Section VI concludes the paper.

\section{RELATED WORK}

Sweetser and Wyeth proposed the GameFlow [9] model where eight overall goals were defined (core elements): concentration, challenge, skill, control, clear goals, feedback, immersion, and social engagement. These goals are in turn based on a number of criteria to evaluate enjoyment of games. Jegers adapted this model to pervasive games domain by examining characteristics and features of pervasive games including mobile/place-independent gameplay, social interaction between players, and integration of the physical and 
virtual worlds [8]. A new model based on theoretical analysis trying to explain how pervasive games are enjoyable, the pervasive game flow model, was proposed based on the general GameFlow with some additions, changes, and elaborations. Our work is an empirical study addressing players' attitude to the enjoyment as an outcome by pervasive game.

Similar to our research, there are some empirical studies on physical games and other game genres in literature. For instance [10] is a report of players' behavior with the Dance Dance Revolution (DDR) game. The social and individual phenomenon of DDR is explored from the point of view of the player population due to its long-lasting and ever-growing popularity. Although the survey was initially designed for a specific game, most of the questions are also applicable to other physically and social games, and the large participants (556 from 22 countries of ages 12 to 50) ensure that the data is less biased. Other large scope surveys investigating players' attitudes are like [11], an exploratory interview-based methodology was used to identify salient categories of players' FPS gaming experience. Connolly et al. describes a survey of students' computer game playing habits to see if computer games could be useful for learning in higher education. Among the results, they found that the most recurring reason for playing games were pleasure, relaxation, challenge, achievement and to have control [12]. Faria and Wellington describe a large survey on business simulation games where they focused on how games were first adopted, objectives for game use, and usage of such games. Tychsen et al. present a survey on the motivations for playing single- and multi-player role-playing games [13]. In this survey they found that the motivations for playing were not simple constructs, but rather multiple motivational drivers that are interrelated. In [14], the authors attempt to determine the many aspects that make a successful MMORPG, and they also attempt to ascertain what new and innovative features are expected by the users from the next generation of MMORPGs. Surveying the MMORPG community's perception (122 respondents were received) of previous and current MMORPGs, as well as their expectations of the next generation is used to achieve this goal.

The focus on the surveys presented above was on traditional games. In this paper, we present research on pervasive games using a similar approach. Similarly the mixedreality social game, Capture the flag, uses a survey to rate on its robustness, intuitiveness, excitement and interactivity within a scope of around 30 players [15]. SupaFly is a communitybased virtual soap opera, where the players create characters and then interact through them [16]. 42 subjects were recruited and 25 completed the evaluation where some interesting results were revealed. For instance, the mobile game is not played in a mobile fashion but in a rather immobile way at homes, the integration of the physical and virtual worlds was of limited importance to the players, and the players used the game to facilitate existing social interaction in groups that they belonged to before they played the game. The cross-media game Epidemic Menace used field observations combined with player feedback, discussion, and pre- and post-event questionnaires to evaluate the collaboration between team members, how players liked the device-specific roles, the immersion degree, and more [17]. The result showed that in overall, the players approved of the game concept and liked the mixture of story, movie, body action, and collaboration.

There also exist evaluations towards specific pervasive games. For instance "Hot Potato" is an example of a new category of multiplayer pervasive games that rely on the use of ad hoc mobile sensor networks. The unique feature in such games is that players interact with each other and their surrounding environment by using movement and presence as a means of performing game-related actions, utilizing sensor devices. Through series of experiments the implementation and the response of human players to the game have been evaluated among 23 persons aged between 23 and 37 , with the $75 \%$ of them having an engineering background and the rest coming from other disciplines. The questions posed to the players included overall satisfaction/fun participating in organized game sessions, reactions to enhancements to the hardware platform and the user interface, and about the game performance. The results indicate a very positive response and that the selected class of devices sufficiently can support this type of games [18]. Another pervasive game, HeartBeat, was designed to demonstrate the design vision of Head-Up games that put outdoors play center stage combining the benefits of traditional outdoor games with the opportunities for richer experiences and innovation offered by new media. The evaluation involving 32 children playing outdoors showed how the game promotes physical activity and social interaction between children in ways one would expect from traditional outdoor games [19]. "Meet Your Heartbeat Twin" is an eventtype location-aware game that includes affective computing through the player's live heartbeats. Data collection for this study was done during two different events in July 2008 (18 game sessions and around 10 participates for each session). The correlation analysis of the data demonstrated broad client profiles for pervasive games, covering age, gender and hobbies. The data showed that urban games are clearly a novel experience; they are not an extension neither from video games, nor from mobile phone casual games [20].

Another novel pervasive game, NEAT-o-Games, which aims to stimulate to enough physical activity, also used questionnaires as part of their experimental study to test smoothness of operation, initial perceptions as well as trends in behavioral change. Our survey differentiates from the above surveys and experiments as they are designed for one specific game and are conducted with small scope of players (normally the field testers). Thus the result can hardly be used to evaluate or anticipate players' attitude towards pervasive games in general because the topic is too specific, the subjects are too few, and are not representative for general population.

\section{THE SURVEY}

This section presents our survey on pervasive games. The TeMPS framework for characterizing pervasive games was the starting-point of this survey [7]. The framework classifies pervasive games according to four main perspectives: temporality - addressing the temporal properties, mobility addressing the spatial properties, perceptibility - addressing how the game is mixed with the reality, and sociality addressing how players interact in a game. 
In the first part of the survey, the respondents were asked to give some demographic data such as age, sex, education etc. In the second part, the respondents stated how positive or negative they were towards five game modes for four types of pervasive game concepts: a mobile quiz game, a location-aware game, a proximity-based game, and an augmented reality game. The four games and game modes, described in text, reflect the mobility, perceptibility and sociability perspectives of TeMPS. The third part of the survey focused on how the respondent would like to see characteristics from all four perspectives in TeMPS in a pervasive game. The fourth part of the survey consisted of some open-ended questions about challenges in pervasive games and suggested improvements of the four pervasive games described in the survey. The survey was distributed to 655 persons and 168 responses were received.

\section{A. Description of the Game Concepts and the Game Modes}

In the survey, the respondents were asked to state their attitude towards descriptions of four different game concepts:

Mobile quiz game: Picture a knowledge game where you are introduced to questions about several different subjects. When completing a series of questions, you will receive points based on how many questions you managed to answer correctly. The goal of the game is to complete as many series of questions as possible. The game is played on a portable unit, for example a mobile phone or similar. The scores of the players are available as an online high score list (website).

Location-aware game: In this game, flags are place around a map of your current area. When approaching a flag, you can answer a series of questions to capture the flag. The questions are related to the local area of the flag. For example, one could get questions about places, persons, events related to the location. When completing a series of questions, one will capture the flag, and it will contribute to your overall score as long as you own the flag. The goal of the game is to capture as many flags as possible, achieving the highest possible score. Other players can capture your flags by completing the same questions as you did when you captured the flag.

Proximity-based game: This game is based on previous described game, but players steal flags from others players in another way. Every series of questions that a player completes will be attached to the player. When two players are within a specified range of each other (e.g., 100 meters), the players can initiate a duel. The initiator is called an attacker, while the other player is the defender. The defender chooses the questions the attacker needs to answer. If the attacker gets a higher score than the defender, the attacker wins the duel and one of the defender's flags now belong to the attacker.
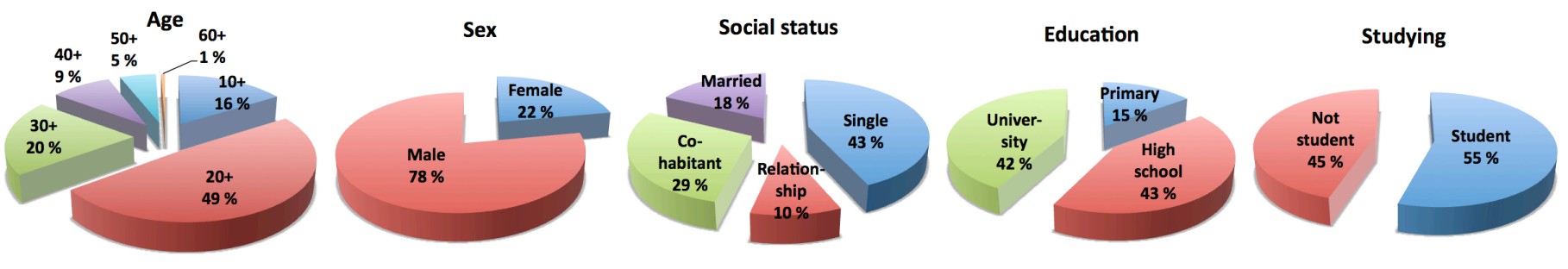
previous concept, but instead of displaying the nodes and players on a game map, players will use built-in video camera of the device to see flags/players. The device will capture video and display virtual representations of flags and players on-top of a video stream. The user will then use this interface to locate flags, and when they come closer than $20 \mathrm{~m}$ of a flag. They may select the node, and start a series of questions to capture it.

Also in the survey, we made the respondents state their attitude towards five different game modes for the game concepts describe above:

- Single player: Play only against the computer.

- Player vs. player: Play against another human player in the virtual world.

- Team vs. team: Human teams play against each other in the virtual world.

- Real player vs. player: Play against another player also in the real world.

- Real team vs. team: Teams play against each other also in the real world.

\section{B. Demographics}

The respondents were requited through two web forums (gamer.no and diskusjon.no), mailing lists of two telecom companies (NetCom and Apps AS) and an internal university web portal for students (NTNU). Figure 1 shows the demographics of the respondents related to age, sex, social status, education and whether they are currently studying respectively. The distribution is not representative for the general Norwegian population, and it clearly reflects that the respondents were recruited from university and technology web forums and mailing lists.

If we consider the age distribution, the majority of the respondents are between 20 and 29 years old (almost 50\%). Respondents of 39 years old or younger represent $85 \%$ of the total. The gender distribution is also very dominant of men (78\%). Singles dominates the social status distribution. The education distribution is about equality divided between respondents that have completed high school and respondents that have completed the university that together represent $85 \%$ of the total. In addition to the distributions shown in Figure 1, we asked the respondents to state their hobbies and how much time they spent on playing video games per week. Based on these two components, we found that $70 \%$ of the respondents could be labeled as "gamers" (vs. non-gamers). The labels "gamers" and "non-gamers" are used in the rest of the paper.
Augmented reality game: This game is based on the

Figure 1. The demongraphics of the repondents 
Along with questions about demographics, the respondents were asked some initial questions about their relation to pervasive games. On the question: "Have you ever played a game where your location was a part of the game?" $12.5 \%$ of the respondents reported that they have played such a game. The survey also asked to specify the location-aware games they have tried, and they mentioned games such as Nintendo Wii games, Killer game, Gowalla, Garmin GPS games, TurfWars, Geocacing, The merchant, and Foursquare. On the question: "Have you tried a game that mixes real and virtual world elements?" 20.7\% answered that they have played such a game, and the examples of such games were Google Earth War, Zombie Run (Android), Tiger Woods 10 (real weather), Burnout Paradise (time of day), games using camera as input, Black and White (weather and time of day), etc. The final question in the first part of the survey asked if a game would benefit from adding pervasive elements. If we consider the respondents as one group, $57 \%$ believed that pervasiveness will add value to a game, $5 \%$ believe it will lessen the value, and $38 \%$ were neutral. If we look at the demographics, there are only small differences in their response. There is a tendency that older and married respondents are more negative to pervasiveness in games. There are only minor differences for gender. The most noticeable difference is between non-gamers and gamers. For non-gamers, $48 \%$ were positive towards pervasive elements in games vs. $60 \%$ for gamers. Further that $11 \%$ of non-gamers were negative towards pervasive elements in games vs. 3\% for gamers. Although non-gamers are more negative for adding pervasive elements into games than gamers, the result is encouraging as $89 \%$ are neutral or positive vs. $97 \%$ for gamers. This means that there might be a strong market for pervasive games for casual and traditional gamers.

\section{THE RESUlTS}

In this section we will present the main results of the survey divided into three parts: Attitude towards game concepts and game modes, attitude towards specific pervasive elements in a game, and an open-ended question.

\section{A. Attitude towards Game Concepts and Game Modes}

This part of the survey is related to the game concepts and game modes described in Section III-A.

\section{Mobile quiz}

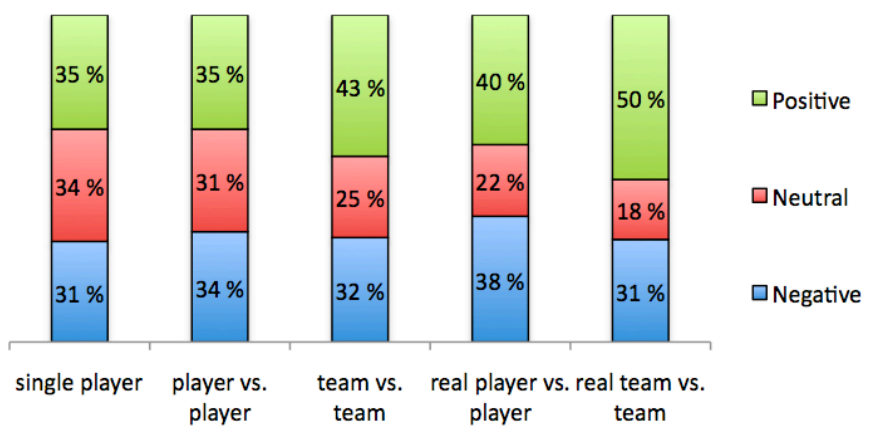

Figure 2. Response about mobile quiz game
The first game concept was a quiz-game playable on a mobile device. Figure 2 above shows the attitude towards five game modes applied to this game concept (see Section III-A). The distribution in Figure 2 shows that the respondents are more positive towards team-based game play and game play involving encounters with real people.

\section{Location-aware}

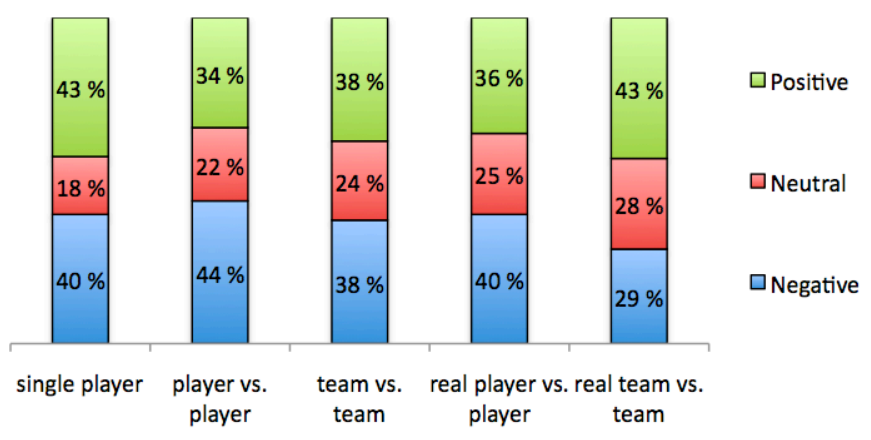

Figure 3. Responses about location-aware game

The second game concept was a location-aware quiz capture-the-flag game. Figure 3 shows the attitude towards five game modes applied to this game concept (see Section III-A). The respondents were generally more negative towards the location-aware game concept. The two most positive game modes were single player and team vs. team with real-world encounters.

\section{Proximity}

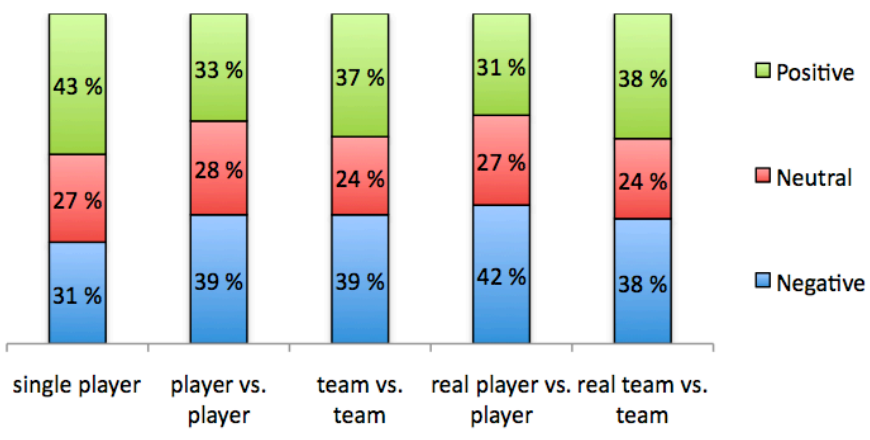

Figure 4. Responses about proximity-based game

The third game concept was a proximity dueling game. Figure 4 shows the attitude towards five game modes applied to this game concept (see Section III-A). For the proximitybased game concept there were also only minor variations among the different game modes were the single player mode received most positive response.

The forth and last game concept was an augmented reality game that mixed real and the virtual world. Figure 5 (on next page) shows the attitude towards five game modes applied on this game concept (see Section III-A). The augmented reality game concept received the most negative responses. The game mode that received most positive responses was team vs. team with real world encounters. 


\section{Augmented reality}

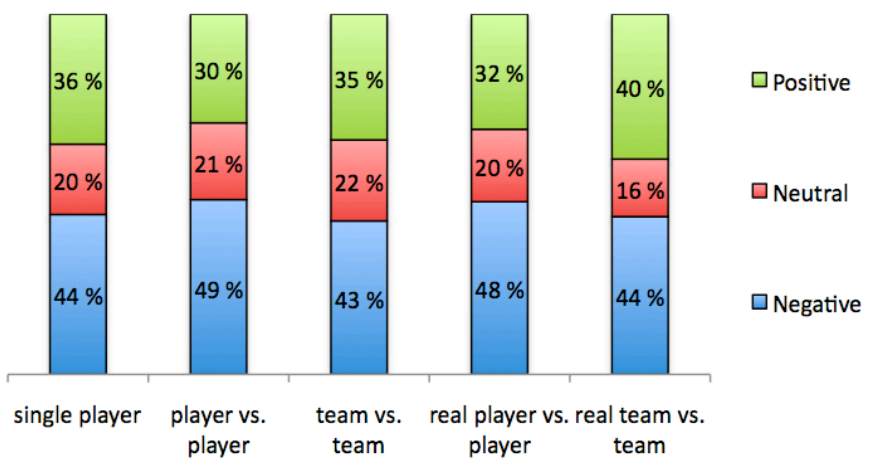

Figure 5. Responses about augmented reality game

Figure 6 shows a comparison of the responses for the four game concepts regardless of game modes. The figure shows some minor variations between the four game modes, where the mobile quiz has most positive responses and augmented reality has most negative responses.

\section{Game concepts}

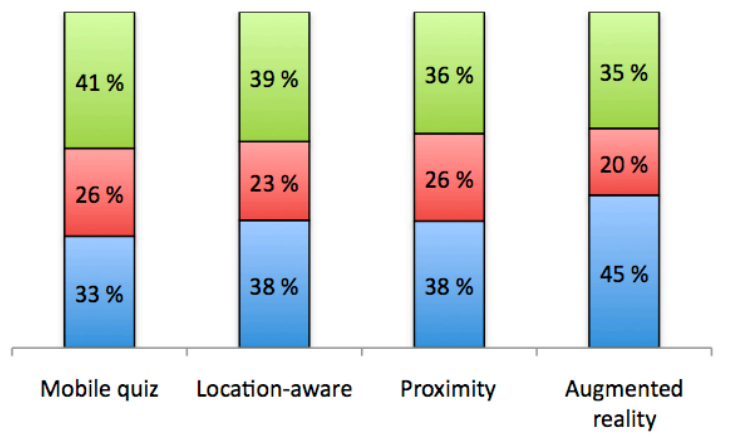

$\square$ Neutral

$\square$ Negative

Figure 6. Responses about the game concepts regardless of game modes

\section{Game modes}

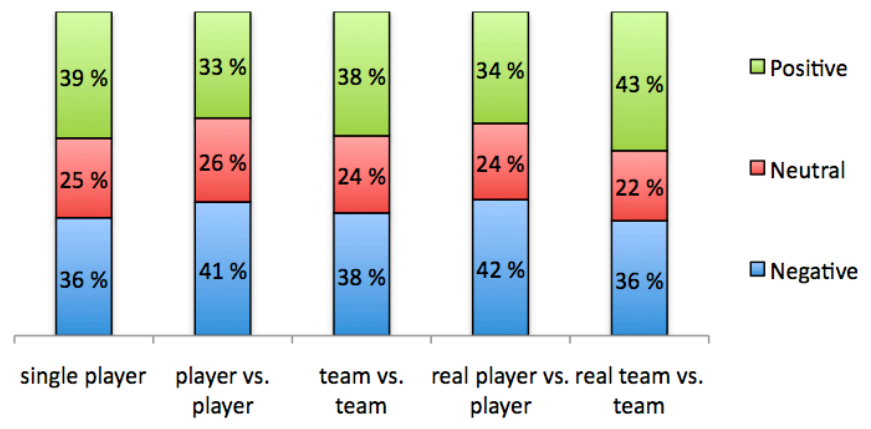

Figure 7. Responses about game modes regardless of game concept

Figure 7 shows a comparison of the responses for the given game modes regardless of game concept. The most noticeable difference for game modes is that there is that the respondents are most negative towards player vs. player game mode both for virtual and real world.
The part of our survey related to game concepts and game modes did not reveal any significant differences. There is a tendency that the proximity and augmented game concepts were less popular than the mobile quiz and location-aware game concepts. Further that the player vs. player modes are less popular than the single player and team-based game modes.

\section{B. Attitude towards Specific Pervasive Elements}

This part of the survey was divided into the four perspectives of the TeMPS framework temporality, mobility, perceptibility, and sociality, and an additional perspective on presentation not being a part of TeMPS.

The temporality perspective is related to the timing of the game. In the survey the respondents were asked to express their attitude towards that the game could be played in a fixed amount of time, could be played anytime or could be played asynchronous. The results are shown in Figure 8. The figure clearly shows that the respondents prefer that a pervasive game can be played anytime. Also the respondents were much more positive towards a game that could be played in a fixed amount time than an asynchronous game.

\section{Temporality}

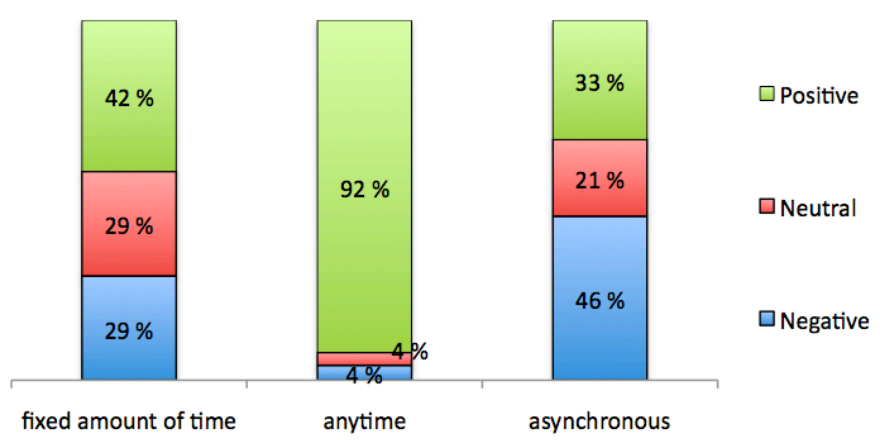

Figure 8. Responses about temporarity in pervasive games

The mobility perspective related to whether the player must physically move to play the game. Figure 9 shows the responses of the mobility perspective in pervasive games. The respondents were generally more positive towards that games should be possible to play anywhere vs. games that are dependent on being at a specific location.

\section{Mobility}

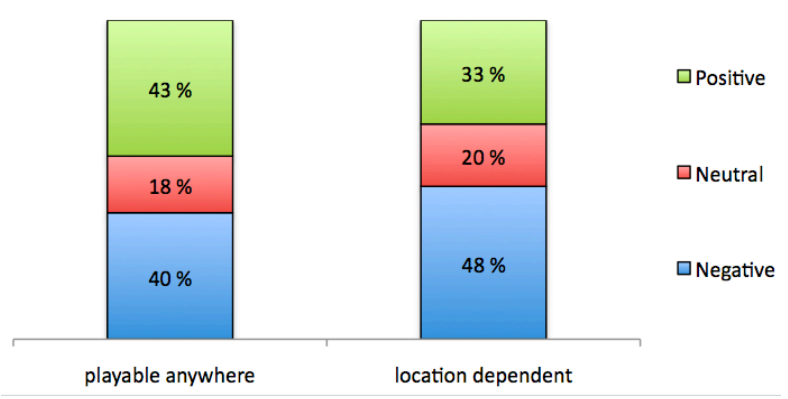

Figure 9. Responses about mobility in pervasive games 
The perceptibility perspective relates to how the user could control or affect the game through body gestures recorded by a camera, audio commands recorded by a microphone, sensors monitoring the body (e.g. blood pressure, heart-beat, body temperature etc), movement to a different physical location, and movement of a physical object. The results are shown in Figure 10. The results show that there are minor variations for all ways of controlling or affecting the game apart from voice control. The respondents were very negative towards controlling a pervasive game using audio. Real player movement (change location) was the item that got most positive responses.

\section{Perceptability}

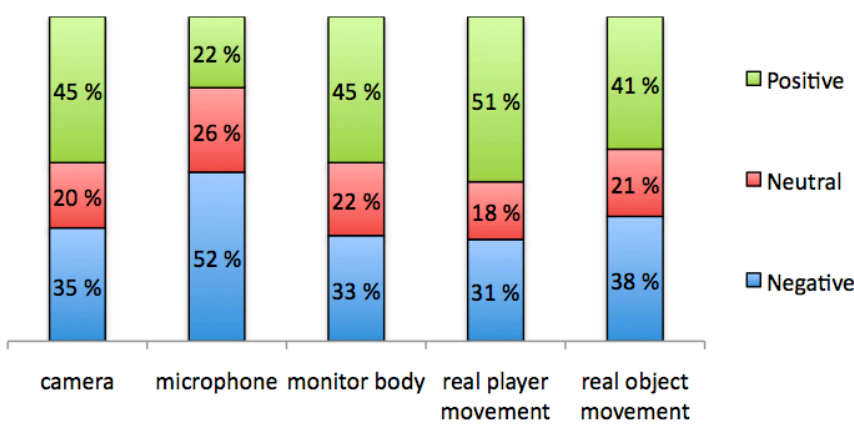

Figure 10. Responses about perceptability in pervasive games

The sociality perspective relates to how the players in the game interact. The respondents were asked to give their opinion about how competition, cooperation, communication and collaborative learning would affect a pervasive game. The results are shown in Figure 11. The results show that to provide support for cooperating and communication were regarded as the two most positive social aspects of a pervasive game. On the other side of the scale, collaborative learning was the regarded as the least positive aspect.

\section{Social}

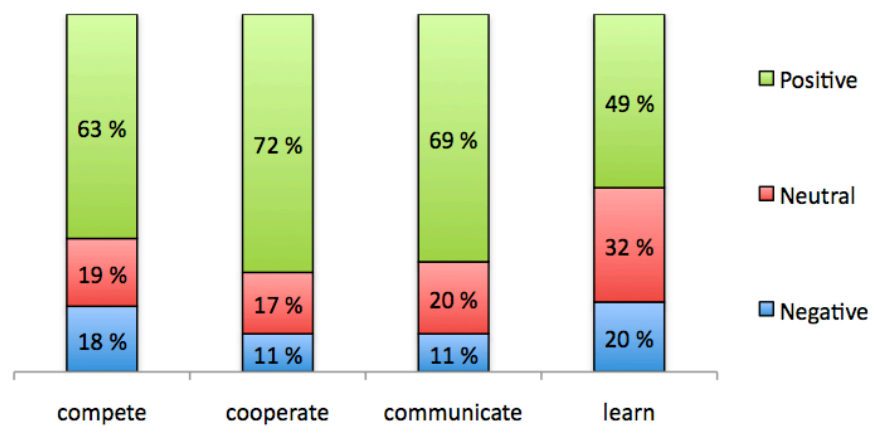

Figure 11. Responses about sociality in pervasive games

The presentation perspective describes how the player of a pervasive game should get responses from the game. The respondents where asked to evaluate the following responses: computer graphics, mixing of real video and computer graphics, sound, physical feedback such as vibration or similar, and physical movement of real objects (e.g. open a door or similar). The results are shown in Figure 12. The results reveal some very noticeable preferences in how the respondents want feedback from the game. The respondents showed that they where quite conservative in how they wanted the game to respond. The three feedback mechanisms that received most positive responses where computer graphics, sound and physical feedback (e.g. controller vibration). This is the feedback you find in any traditional consol game today.

\section{Presentation}

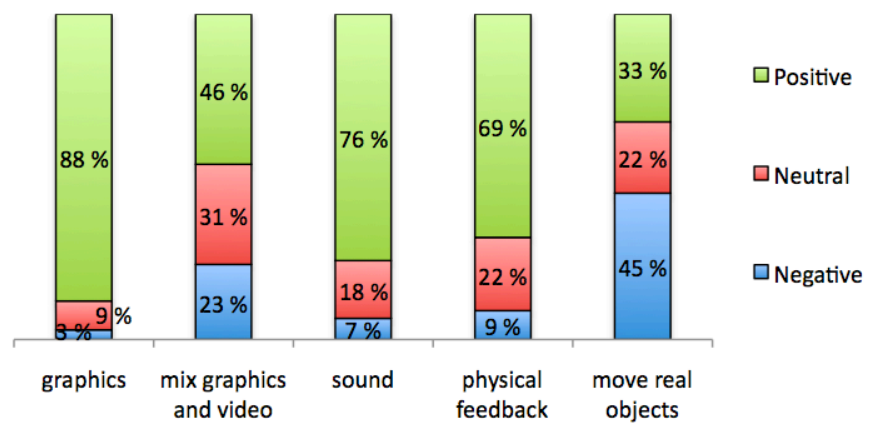

Figure 12. Responses about presentation in pervasive games

\section{Open-ended Question}

The open-ended question was: "what do you think are the most important challenges of pervasive games". Here is a summary of the responses we received that was most frequently mentioned and/or relevant to the findings in the other three parts of the survey and can serve as possible explanations for differences found:

- "Voice control is not good enough and does not work in practice."

- "A challenge for pervasive game is to make it possible to allow hard competition without getting physically harmed."

- "A challenge with alternative control mechanisms (voice, physical) is that they are not responsive enough (too slow)."

- "The technology is not invisible enough to provide a full pervasive gaming experience."

- "Pervasive games can easily become to complex for the player making them tedious and less fun to play."

- "A challenge for pervasive games is often that the technology is prioritized at the expense of gameplay."

- "A challenge is to keep the player engaged for a long time, as the novelty aspect of the wears off."

- "Most people use computer games to relax. Pervasive games can be hard physical work."

- "Pervasive games must avoid that the player looks like a looser in public when he is playing the game."

- "The main challenge of pervasive game development is to have focus on content and not the technology."

- "Privacy is always a big issue for pervasive games."

- "A challenge for pervasive games is how far games can be pushed before they become too realistic. It should be possible to distinguish between the game and the real world." 
- "It is a challenge to melt technology and game into one coherent experience."

- "Pervasive games take too much time to start playing and too much time to play (too long game sessions)."

- "A major challenge is to ensure that the quality of the game is not reduced because it is a pervasive game."

- "It is challenge to have a very engaging game concepts that includes humor and surprises."

- "Pervasive games demands higher realism in graphics quality to minimize the gap between virtual and real world."

Here are some responses to our four game concepts:

- "Mobile knowledge-based games seams interesting."

- "The games can be very enjoyable if they are properly designed and implemented."

\section{DISCUSSION}

This section discusses the results in the survey and addresses the threats to validity.

\section{A. Discussion about the Results}

A main part of our survey investigated the respondents' attitude towards some game concepts and game modes we have described. The results did not reveal any substantial differences between the various game concepts and game modes, but there is a tendency that they were most positive about the mobile quiz game concept and most negative about the augmented reality game concept. One reason for the small difference in the responses to these game concepts can be that they were too similar and did not fully explore the possibilities of pervasive gaming. Another potential explanation can be that the game concepts are based on the same core mechanics (the quiz game) and thus provide little variability. Similarly, we did not find big differences for the five game modes, but there were some recognizable patterns. The respondents seam to prefer single player and team-based game modes to player vs. player game modes. One possible explanation to this result can be that player vs. player can get more personal when it is played in a pervasive game as parts of the gameplay happens in the real world.

In another main part of the survey, we looked at the attitude towards specific pervasive elements. This part of the survey revealed some interesting results. First of all the respondents clearly preferred that a pervasive game should be played anytime and thus have little restrictions related to temporal characteristics. Asynchronous gameplay was the least liked, which makes sense in a pervasive environment where the players invest time to move around the in real world. Further, the respondents clearly preferred that a pervasive game could be played anywhere with little restrictions about being at specific places as a part of the gameplay. Regarding what kind of input the respondents prefer in a pervasive game, the main finding was that they were negative biased towards audio input (voice control). One reason for this was given in the openended questions that voice control does not work well enough (immature). Another possible reason could be that people generally does not want to make fool out of themselves by shouting audio commands to a computer when other people are around (this was also mentioned in the open-ended question).
Regarding the social factors of pervasive games, the respondents were most positive towards elements of cooperation and communication being a part of the game. They were most negative to having collaborative learning aspects as a part of the game. The latter could be explained by the fact that over half of the respondents were students. Regarding how pervasive games should be presented to the user, the traditional game outputs (graphics, audio and physical feedback) received most positive responses. This is the kind of presentation any recent console game has today, and shows that the respondents were quite conservative in how they prefer a game to be presented to the player.

The open-ended question pointed out many areas that are critical for pervasive games in order to succeed. A majority of the feedback focused on two issues: 1) that the technology should not get in the way of the gameplay and 2) that the content of the game is the most important aspects. We believe that these are two major factors why pervasive games have not become big commercial successes so far. For many pervasive games implemented by researchers, it seams that it is the technology that was the starting-point of when developing the game and not a novel idea of game mechanics or a game play. To make pervasive games more engaging and fun to play, it is essential that the underlying technology is an enabler to construct a novel idea, and not vice versa.

\section{B. Threats to Validity}

We used an online questionnaire in this survey, which may prevent people who does not frequently use the Internet from responding. Further, we provided prizes such as iPod Touch, mobile application gift cards, and electronics gift cards to be drawn to stimulate to higher number of respondents. These prizes were obviously more attractive to people who are interested in electronics. The gender distribution (male $78 \%$ vs. female $22 \%$ ) reveals bias from these two causes.

We recognize that the enjoyment of pervasive elements is highly dependent on game settings. A good design may use pervasive technology wisely that satisfies most of the players, while a poor design could ruin the gaming experience. The survey used very simple game concepts, which were supposed to be neutral in terms of design quality. We made the game concepts in such a way that they could be combined with various game modes for different player configurations. The little variation on the responses we received on the various game concepts could be affect by the fact that the game modes had too little variation and were too general. For us, this was a trade-off to make it possible to feature variations in game modes. We suspect that a more detailed description of game modes with more variation would have given more variation in the results as well. We also acknowledge that our game concepts and game modes were insufficient to represent all the possibilities of pervasive games.

\section{CONCLUSION}

This paper presents the results from a survey where we wanted to assess people's attitude towards pervasive games in general and some specific features of pervasive games. The demographic of our respondents is not representative if we 
consider the population as a whole, but it is fairly representative if we consider the most likely players of such games. Our first research question (RQ1) was about whether pervasive gaming is an attractive concept to gamers and people in general. We found that a majority of the respondents were positive that pervasive features would add value to a game (57\%). However, we found noticeable differences between gamers and non-gamers. For non-gamers, only $48 \%$ were positive while for gamers $60 \%$ were positive. Also we found that $89 \%$ of the non-gamers and $97 \%$ of the gamers were neutral or positive to the statement that pervasiveness added value to a game.

The second research question (RQ2) focused on how the respondents perceived various pervasive game concepts and game modes. This part of the survey did not reveal any huge differences in preferences. We found a tendency that game concepts related to location proximity and augmented reality were less popular than simpler pervasive game concepts. Further, that player vs. player game modes were less attractive than single player and team-based game modes. It seams that the respondents prefer the concepts they are most used to and are more skeptic to unfamiliar game concepts and modes.

The third research question (RQ3) looked at what pervasive characteristics are desirable to have in a game. This part of the survey showed that the respondents clearly had some preferences in what pervasive characteristics a pervasive game should have. The most noticeable findings were that the respondents preferred that a pervasive game should be playable anytime, anywhere, that audio should not be used for game input, that the game should facilitate competition, cooperation and communication, and that the feedback to the user should be through graphics, sound and physical feedback. Especially, the latter, shows that the respondents were quite conservative in how they perceive that a game should interact with the user.

The open comments in the survey also gave some interesting insights into the challenges of pervasive games. Many of the comments were related to where the focus of such games should be, e.g. on content and gameplay rather than technology. An interesting comment was on the fact that people play games to relax, and that pervasive games do not fit well into this category. Finally, even though mobile technology has come far, the technology is still not invisible and work well enough to give the perfect pervasive experience.

This paper did not get any conclusions on whether pervasive games will be a huge success in the future. There are still many issues that must be resolved before people will involve in pervasive games on a large scale. However, the survey gave some indicators to areas that must be paid some extra attention when designing a pervasive game.

\section{REFERENCES}

[1] [C. Magerkurth, A. D. Cheok, R. L. Mandryk, and T. Nilsen, "Pervasive games: bringing computer entertainment back to the real world," $A C M$ Computers in Entertainment, vol. 3, pp. 4-4, 2005.
[2] I. Smith, S. Consolvo, and A. LaMarca, "The Drop: pragmatic problems in the design of a compelling, pervasive game," Computer Entertainment, vol. 3, pp. 4-4, 2005.

[3] [S. Benford, A. Crabtree, M. Flintham, A. Drozd, R. Anastasi, M. Paxton, N. Tandavanitj, M. Adams, and J. Row-Farr, "Can you see me now?," ACM Trans. Computer Human Interaction, vol. 13, pp. 100$133,2006$.

[4] O. Sotamaa, "All The World's A Botfighter Stage: Notes on Locationbased Multi-User Gaming," in Computer Games and Digital Cultures Conference Tampere, Finland: Tampere University Press, 2002, pp. 3544.

[5] K. Jegers, "Elaborating eight elements of fun: Supporting design of pervasive player enjoyment," ACM Computers in Entertainment, vol. 7, pp. 1-22, 2009.

[6] E. Nieuwdorp, "The Pervasive Discourse: An Analysis," $A C M$ Computers in Entertainment, vol. 5, August 2007.

[7] G. Hong, H. Trætteberg, A. I. Wang, and M. Zhu, "TeMPS: A Conceptual Framework for Pervasive and Social Games," in Third IEEE Information Conference on Digital Game and Intelligent Toy Enhanced Learning Kaohsiung, Taiwan, 2010.

[8] K. Jegers, "Pervasive Game Flow: Understanding Player Enjoyment in Pervasive Gaming," ACM Computers in Entertainment, vol. 5, April 2007.

[9] P. Sweetser and P. Wyeth, "GameFlow: A model for evaluating player enjoyment in games," ACM Computers in Entertainment, vol. 3, July 2005.

[10] J. Hoysniemi, "International survey on the Dance Dance Revolution game," ACM Computers in Entertainment, vol. 4, p. 8, 2006.

[11] D. Clarke and P. R. Duimering, "How computer gamers experience the game situation: a behavioral study," ACM Computers in Entertainment, vol. 4, p. 6, 2006.

[12] T. M. Connolly, E. A. Boyle, M. H. Stansfield, and T. Hainey, "A survey of students' computer game playing habits," Advanced Technology for Learning, vol. 4, pp. 218-223, 2007.

[13] A. Tychsen, M. Hitchens, and T. Brolund, "Motivations for play in computer role-playing games," in Proceedings of the 2008 Conference on Future Play: Research, Play, Share Toronto, Ontario, Canada: ACM, 2008.

[14] L. Achterbosch, R. Pierce, and G. Simmons, "Massively multiplayer online role-playing games: the past, present, and future," $A C M$ Computers in Entertainment, vol. 5, pp. 1-33, 2007.

[15] A. D. Cheok, S. L. Teo, L. Cao, and L. N. Thang, "Capture the Flag: A Multiplayer Online Game for Phone Users," in Proceedings of the Ninth IEEE International Symposium on Wearable Computers: IEEE Computer Society, 2005.

[16] K. Jegers and M. Wiberg, "Pervasive Gaming in the Everyday World," IEEE Pervasive Computing, vol. 5, p. 78, 2006.

[17] I. Lindt, J. A. N. Ohlenburg, U. T. A. Pankoke-Babatz, and S. Ghellal, "A report on the crossmedia game epidemic menace," ACM Computers in Entertainment, vol. 5, p. 8, 2007.

[18] I. Chatzigiannakis, G. Mylonas, O. Akribopoulos, M. Logaras, P. Kokkinos, and P. Spirakis, "The "Hot Potato" Case: Challenges in Multiplayer Pervasive Games Based on Ad hoc Mobile Sensor Networks and the Experimental Evaluation of a Prototype Game," HumanComputer Interaction, February 2010.

[19] R. Magielse and P. Markopoulos, "HeartBeat: an outdoor pervasive game for children," in Proceedings of the 27th international conference on Human factors in computing systems Boston, MA, USA: ACM, 2009.

[20] I. Flammer, C. Yan, W. Ka, A. Flammer, J.-P. Cheung, and R. Pellerin, "Player Feedback Evaluation: Indicating Mass Public Potential for Pervasive Games," in Proceedings of the 8th International Conference on Entertainment Computing Paris, France: Springer-Verlag, 2009. 